\title{
Currency Option Pricing under Stochastic Interest Rates and Extended Normal Distribution
}

\author{
Yu-hong Liu ${ }^{1}$, Yu-Chen Lin ${ }^{2, *}$, Ya-hsin Hung ${ }^{1}$ \\ ${ }^{1}$ Graduate Institute of Finance, National Cheng Kung University, Taiwan \\ ${ }^{2}$ Department of Accountancy, National Cheng Kung University, Taiwan
}

Copyright $\mathrm{O} 2016$ by authors, all rights reserved. Authors agree that this article remains permanently open access under the terms of the Creative Commons Attribution License 4.0 International License

\begin{abstract}
In this paper, we have constructed a model to price currency option. It contributes to releasing some assumptions the Black-Scholes' (1973) model makes. One of them is that the log price of asset doesn't follow a normal distribution any more. The other one is the interest rates in the domestic and foreign countries become stochastic. This general formula is first proposed by Amin and Jarrow (1991). Based on this model, we build extended normal distribution model [developed by Ki, Choi, Chang and Lee (2005)] under the assumption of stochastic interest rate economy. In numerical examples, our proposed model would be compared with Amin and Jarrow (1991) under CIR [Cox, Ingersoll and Ross (1985)] interest rate term structure. Furthermore, Monte Carlo simulation is used to provide another outcome to be another comparative example. Finally, we think that the proposed model provides more correct currency option prices when taking account of stochastic interests and extended normal distribution. The drawback of the Black-Scholes' formula which fails to catch the volatility smile effect is resolved by using the proposed model. The market participants can use the actual market data to calibrate the parameters of the proposed model and use the proposed model to price the currency options and derivatives accurately.
\end{abstract}

Keywords Currency Option, Stochastic Interest Rate, Kurtosis, Skewness, Extended Normal Distribution

\section{Introduction}

Currency options have been traded publicly for more than 30 years. In earlier years, this trading is largely made in the Campa interbank market. With the globalization and development of multinational enterprises, currency option is widely traded and used. It is not only a hedge instrument but also a commonly traded currency derivative. Central banks buy it to manage exchange rate as well. The Black-Scholes' model (1973) provides a closed-form formula for option pricing. It is also applied to price European currency options. Biger and Hull (1983) build the currency pricing model based on the same assumptions and structures with Black-Scholes' instead of replacing the stock dividend rate by the foreign risk-free interest rate.

This paper is worked to solve for two deficiencies which Black-Scholes make. It extends Black-Scholes' framework by incorporating the stochastic interest rates and the non-normal skewness and kurtosis distribution for log price of exchange rate rather than standard normal distribution. It is generally agreed that the return of the underlying asset doesn't follow normal distribution. We try to divide present studies into three categories which are non-random walk, jump-diffusion and volatility smile. Black-Scholes' model makes the assumptions that the asset price follows geometric Brownian motion so that it would be a random walk over time. The empirical results show floating exchange rates disobey it due to the stochastic property.

Jump-diffusion of the exchange rate and its volatility behavior implies the symmetric bell-shaped distribution can't account for the real probability density. Heston (1993) build a closed-form solution for bond and currency options with stochastic volatility. Scott (1997) develops Fourier inversion formula for distribution function to revise for jump-diffusion model with stochastic volatility and stochastic interest rates. Lewis (2001) proposes a simple pricing formula for general jump diffusion by incorporating Levy process.

Volatility smile exists in currency option; the volatility is relative low for at-the-money option and there is a U-shaped pattern of implied volatility with different strike price. To overcome this deficiency, Dupire (2004) prices option by allowing volatility to be time-dependent and explains volatility with two variables, maturity and exercise price. Kou (2002) builds jump-diffusion pricing model to consider three properties: leptokurtic feature, volatility smile and analytical tractability. Chesney and Scott (1989) modify Black-Scholes' model to let the variance of currency be stochastic. Besides that, they estimate the parameter by observing actual currency price and compare the random 
volatility model with the traditional currency option model.

In previous research articles, there are many probability distributions proposed to sketch non-normal patterns, such as exponential distribution and Weibull distribution. In particular, Jarrow and Rudd (1982) use Edgeworth series expansion to replace standard normal distribution to price. Corrado and Su (1996) apply the Gram-Charlier series expansion as an alternative distribution. Nevertheless, $28 \%$ of the locus of the Gram-Charlier series expansion is negative. Sherrick, Garcia and Tirupattur (1996) suggest the use of Burr type III distribution by analyzing soybean option and future prices from the Chicago Board of Trade. Moreover, they conclude Burr type III substantially provide more accurate variances of underlying asset than lognormal distribution dose. Ki, Choi, Chang and Lee (2005) extend the Gram-Charlier series to build extended normal distribution to price stock option. They make the conclusion that pricing option under extended normal distribution better than under the classical Black-Scholes formula.

Grabee (1983) is the first scholar who proposes currency option pricing model under stochastic interest rates. He verifies the pricing formula by integrating default-free bonds as discount factors, but the interest term structure isn't defined clearly in his paper. Hilliard, Madura and Tucker (1991) develop the pricing model, being closed to the Black's futures option pricing model except that the constant variance is replaced by an integral form of continuous instantaneous volatility measure, and it is assumed that domestic and foreign bond prices have local variances depending only on time. They simplify the model without considering the stochastic property of the volatility and don't interpret the effect on exchange rate caused by interaction between the two interest rates. In recent years, Choi and Marcozzi (2003) develop the currency option pricing model under Ho-Lee term structure considering the state variable to be the short rates of interest and the cross currency exchange rate. They also show the numerical result obtained from a finite element approximation and the analytic solution derived by Amin and Jarrow (1991).

In this paper we try to build a general formula by allowing interest rate to be stochastic over time. Amin and Jarrow (1991) develop a pricing formula with the term structure model offered by Heath (1987). We reform it by assuming the underlying asset return follows extended normal distribution [Ki, Choi, Chang and Lee (2005)].

The article is organized as follows. The next section is used to define the notations. The section 2 of this paper mainly explains two concepts, the methodology model and how interest varies under stochastic economy. Furthermore, it contributes to a general pricing formula for currency options in a model which allows domestic and foreign interest rate to change randomly and when the underlying asset follows extended normal distribution. The final section would present the currency prices calculated by our proposed model and compare them with the numerical results simulated by Monte Carlo method. Finally we draw the conclusion.

\section{Notations}

$S_{t}$ : the current spot currency price at time $t$ of 1 unit the foreign currency in terms of the domestic currency.

$S_{T}$ : the currency price at maturity time $T$.

$X$ : the exercise price.

$C(t, T, X):$ the present value of European currency call maturing at time $T$ with strike price $X$.

$r_{d}$ : the domestic risk-free interest rate.

$r_{f}:$ the foreign risk-free interest rate.

$\sigma_{s}^{2}:$ the instantaneous variance of the return on a foreign currency holding.

$T:$ the maturity date. $\tau=T-t$ : time remaining until option matures.

$f_{d}(t, T)$ : the domestic forward interest rate contracted at time $t$ for instantaneous borrowing and lending at time $T$ with $0 \leq t \leq T$.

$f_{f}(t, T)$ : the foreign forward interest rate contracted at time $t$ for instantaneous borrowing and lending at time $T$ with $0 \leq t \leq T$.

$P_{d}(t, T)$ : the time $t$ price of a pure discount bond paying 1 unit of the domestic currency at time $T$ for $t \in[0, T]$. $P_{d}(t, T)=\exp \left[-\int_{t}^{T} f_{d}(t, u) d u\right]$

$P_{f}(t, T)$ : the time $t$ price of a pure discount bond paying 1 unit of the foreign currency at time $T$ for $t \in[0, T]$. $P_{f}(t, T)=\exp \left[-\int_{t}^{T} f_{f}(t, u) d u\right]$
$B_{d}(t): \exp \left[\int_{0}^{t} r_{d}(u) d u\right]$ for $t \in[0, T]$. This is the domestic money market account. It is denominated in the domestic currency.

$B_{f}(t): \exp \left[\int_{0}^{t} r_{f}(u) d u\right]$ for $t \in[0, T]$. This is the foreign money market account. It is denominated in the foreign currency.

$N($.) : the cumulative standard normal distribution function.

$n($.$) : the standard normal distribution function.$

\section{The Methodology and Model}

\subsection{Extended Normal Distribution}

Ki, Choi, Chang, and Lee (2005) revise Black-Scholes' model by extending normal distribution to price currency options. There are several probability distributions proposed to replace standard normal distribution to solve the 
characteristics of skewness and kurtosis in option pricing, such as Gram-Charlier distribution. In this paper, we make the critical assumption that the log prices of all underlying assets follow extended normal distribution.

The important parameters for $k>3$ as follows

$$
\begin{gathered}
p=\frac{3}{k+3}, \\
\alpha^{2}=1-\frac{1}{p} \sqrt{p(1-p)\left(\frac{k}{3}-1\right)} \\
\beta^{2}=1+\frac{1}{1-p} \sqrt{p(1-p)\left(\frac{k}{3}-1\right)}
\end{gathered}
$$

where $k=\frac{\mu_{4}}{\sigma^{4}}$, the kurtosis, is a measure of the peakness of the probability distribution of random variable; $\mu_{4}$ is the fourth moment about the mean and $\sigma$ is the standard deviation. $\xi=\frac{\mu_{3}}{\sigma^{3}}$, the skewness, is a measure of the asymmetry of the probability distribution of random variable, where $\mu_{3}$ the third moment about the mean. $l_{k}(x)$ is the combination of two normal distribution with weight $p$ and $(1-p)$.

$$
l_{k}(x)=p h_{0, \alpha}(x)+(1-p) h_{0, \beta}(x)
$$

where $h_{0, \alpha}(x)$ and $h_{0, \beta}(x)$ are two normal distribution with mean 0 and standard deviation $\alpha$ and $\beta$ respectively.

For the skew parameter, $\xi$, we can express $J_{\xi, k}(x)$ as

$$
\begin{aligned}
J_{\xi, k}(x) & =l_{k}(x)-\frac{\xi}{6} l_{k}^{\prime \prime \prime}(x) \\
& =p\left\{1+\frac{\xi}{6 \alpha^{6}}\left(x^{3}-3 \alpha^{2} x\right)\right\} h_{0, \alpha}(x)+(1-p) \\
& \left\{1+\frac{\xi}{6 \beta^{6}}\left(x^{3}-3 \beta^{2} x\right)\right\} h_{0, \beta}(x)
\end{aligned}
$$

In this model, we can let the level of kurtosis and skewness not only be 3 and 0 respectively. The kurtosis and skewness parameters can be decided after surveying the real conditions, and it is anticipated to get a more precise option price. $l_{k}^{\prime \prime \prime}(x)$ is the third partial differentiation of $l_{k}(x)$.

Definition 1: If a random variable $Y$ follows extended normal distribution with mean $m$, standard deviation $\sigma$, skewness $\xi$, and kurtosis $k$. We can show the probability distribution function as

$$
f_{m, \sigma, \xi, k}(y)=\frac{1}{\sigma} J_{\xi, k}(x)\left(\frac{y-m}{\sigma}\right)
$$

Then the call value at time $T$ is

$$
\begin{array}{r}
C(T, T, X)=\left[\max \left(S_{T}-X\right), 0\right] \\
=\int_{\frac{\log X-m}{s}}^{\infty}[\exp (s y+m)-X] J_{\xi, k}(y) d y
\end{array}
$$

The moment-generating of extend normal distribution is presented as

$$
M(\theta)=\exp (m \theta) \int_{-\infty}^{\infty} \exp (\sigma \theta z) J_{\xi, k}(z) d z
$$

When $\theta=1$ we can obtain the mean of the density function

$$
\begin{aligned}
m & =\log [M(1)]-\log \left\{\left(1+\frac{\xi s^{3}}{6}\right)\left[p e^{\alpha^{2} s^{2} / 2}+(1-p) e^{\beta^{2} s^{2} / 2}\right]\right\} \\
& =\log [M(1)]-\log (A+B)-\log \left(1+\frac{\xi s^{3}}{6}\right)
\end{aligned}
$$

where

$$
A=p e^{\alpha^{2} s^{2} / 2}, B=(1-p) e^{\beta^{2} s^{2} / 2}, s=\sigma \sqrt{T} .
$$

$s$ is the instantaneous standard deviation of the log price. $M(1)$ is the first moment restriction of the underlying asset under risk-neutral measure.

\subsection{Pricing Currency Options under Stochastic Economy}

Since the pricing model is based on stochastic interest rates, the concepts and assumptions of stochastic economy defined by Amin and Jarrow (1991) are discussed briefly here before entering the major model.

The domestic and the foreign forward interest rate dynamics

$d f_{d}(t, T)=\alpha_{d}(t, T, \omega) d t+\sum_{i=1}^{2} \sigma_{d i}\left(t, T, f_{d}(t, T)\right) d W_{i}(t)$
$d f_{f}(t, T)=\alpha_{f}(t, T, \omega) d t+\sum_{i=2}^{3} \sigma_{f i}\left(t, T, f_{f}(t, T)\right) d W_{i}(t)$,

for all $\omega \in \Omega, t \leq T$ and $0 \leq T \leq \tau$

The forward domestic and foreign interest rates are affected by two dimensions, ( $d W_{1}(t)$ and $\left.d W_{2}(t)\right)$, and $\left(d W_{2}(t)\right.$ and $\left.d W_{3}(t)\right)$. They have one common random shock, $d W_{2}(t)$. This means the changes of both the domestic and the foreign interest rates would be affected by one certain reason.

The instantaneous variance of the domestic and the 
foreign forward interest rates are

$$
\begin{aligned}
& \operatorname{var}\left(f_{d}(t, T)\right)=\left[\sigma_{d 1}^{2}\left(t, T, f_{d}(t, T)\right)+\right. \\
& \left.\sigma_{d 2}^{2}\left(t, T, f_{d}(t, T)\right)\right] d t
\end{aligned}
$$

and

$$
\begin{gathered}
\operatorname{var}\left(f_{f}(t, T)\right) \\
=\left[\sigma_{f 2}^{2}\left(t, T, f_{f}(t, T)\right)+\sigma_{f 3}^{2}\left(t, T, f_{f}(t, T)\right)\right] d t .
\end{gathered}
$$

The instantaneous covariance between the domestic forward interest rate and the foreign forward interest rate is $\left(\sigma_{d 2} \sigma_{f 2}\right) d t$.

The stochastic process of the domestic and foreign risk-free bonds are written as

$$
\begin{gathered}
\frac{\mathrm{d} P_{k}(t, T)}{P_{k}(t, T)}=\left[r_{k}(t)+b_{k}(t, T)\right] d t+\sum_{i=1}^{2} a_{k i}(t, T) d W_{i}(t) \\
k \in[d, f]
\end{gathered}
$$

where

$$
\begin{gathered}
a_{k i}(t, T)=-\int_{t}^{T} \sigma_{k i}\left(t, u, f_{k}(t, u)\right) d u \quad \text { for } i=1,2 \\
b_{k}(t, T)=-\int_{t}^{T} a_{k}(t, u, \omega) d u+\frac{1}{2} \sum_{i=1}^{2} . \\
{\left[\int_{t}^{T} \sigma_{k i}\left(t, u, f_{k}(t, u)\right) d u\right]^{2}}
\end{gathered}
$$

The drift term of the foreign discount bond is the combination of interest rate and liquidity premium. The instantaneous variances of the two discounted bonds are depended on two variables.

The dynamic process for spot exchange rate is

$$
\frac{d S_{t}}{S_{t}}=\mu_{d}(t)+\sum_{i=1}^{4} \delta_{d i}(t) d W_{i}(t)
$$

where $S_{t} \geq 0$ a.s. $P$ and $\left(\mu_{d}(t), \delta_{d i}(t)\right.$ for $\left.i=1, \ldots, 4\right)$ are subject to some regularity restrictions; see Amin and Jarrow (1991).

The dynamic process of spot exchange rate is based on four dimensions, three of them $\left(d W_{1}(t), d W_{2}(t), d W_{3}(t)\right)$ are the same with the terms in the domestic and the foreign interest rate processes. The instantaneous variance and the covariance of exchange rate and domestic forward interest rate are written as

$$
\begin{gathered}
\operatorname{var}\left(\frac{d S_{t}}{S_{t}}\right)=\left[\sum_{i=1}^{4} \delta_{d i}^{2}(t)\right] d t \\
\operatorname{cov}\left(\frac{d S_{t}}{S_{t}}, d f_{d}(t, T)\right)=\left[\sum_{i=1}^{2} \sigma_{d i} \delta_{d i}\right] d t
\end{gathered}
$$

Translating the foreign bond to the domestic currency at time $t$, we have get

$$
P_{f}^{*}(t, T)=P_{f}(t, T) S_{t}
$$

$P_{f}^{*}(t, T)$ is the foreign bond denominated by domestic currency; it also equals to the discounted bond value at time $t$ multiplying the exchange rate at time $t$. The dynamic process of $P_{f}^{*}(t, T)$ is

$$
\begin{aligned}
& \quad \frac{d P_{f}^{*}(t, T)}{P_{f}^{*}(t, T)}=\left[r_{f}(t)+b_{f}(t, T)+\mu_{d}(t)+\right. \\
& \left.+\sum_{i=1}^{4} \delta_{d i}(t) a_{f i}(t, T)\right] d t+ \\
& +\sum_{i=1}^{4}\left[a_{f i}(t, T)+\delta_{d i}(t)\right] d W_{i}(t) \\
& =\mu_{f}^{*}(t) d t+\sum_{i=1}^{4}\left[a_{f i}(t, T)+\delta_{d i}(t)\right] d W_{i}(t)
\end{aligned}
$$

where

$\mu_{f}^{*}(t)=\left[r_{f}(t)+b_{f}(t, T)+\mu_{d}(t)+\sum_{i=1}^{4} \delta_{d i}(t) a_{f i}(t, T)\right]$

The instantaneous standard deviation of $\frac{d P_{f}^{*}(t, T)}{P_{f}^{*}(t, T)}$ is $\sum_{i=1}^{4}\left[a_{f i}(t, T)+\delta_{d i}(t)\right] d t$, equaling to summation of random terms of the foreign bond and exchange rate.

The present value of $P_{f}^{*}(t, T), \frac{P_{f}^{*}(T, T)}{B_{d}(T)}$, discounted by the domestic money market account. We serve the domestic money market account $B_{d}(t)$ as the numerator and get the relative price, $\frac{P_{f}^{*}(t, T)}{B_{d}(t)}$. The value becomes $\frac{P_{f}^{*}(T, T)}{B_{d}(T)}$ at maturity $T$; on the other hand, it implies that $P_{f}^{*}(T, T)$ is discounted by the domestic risk-free rate and $\frac{P_{f}^{*}(T, T)}{B_{d}(T)}$ can be thought as the present value of $P_{f}^{*}(T, T)$.

The following we would explain the price process of $Z_{f}(t, T)$ in detail. 


$$
\begin{gathered}
Z_{f}(t, T)=\frac{P_{f}(t, T) S_{d}(t)}{B_{d}(t)}=\frac{P_{f}^{*}(t, T)}{B_{d}(t)} \\
\frac{d Z_{f}(t, T)}{Z_{f}(t, T)}=\left[r_{f}(t)+b_{f}(t, T)+\mu_{d}(t)-r_{d}(t)\right] d t \\
+\sum_{i=1}^{4}\left[a_{f i}(t, T)+\delta_{d i}(t)\right] d W_{i}^{P}(t) \\
=\beta_{f}(t, T) d t+\sum_{i=1}^{4} \gamma_{f i}(t, T) d W_{i}^{P}(t)
\end{gathered}
$$

For simplicity,

$\beta_{f}(t, T)=\left[r_{f}(t)+b_{f}(t, T)+\mu_{d}(t)-r_{d}(t)\right]$

$\gamma_{f i}(t, T)=\left[a_{f i}(t, T)+\delta_{d i}(t)\right]$.

Define a new measure $Q$ such that its Randon-Nikodym derivative is given by

$$
\frac{d Q}{d P}=\exp \left[\sum_{i=1}^{4} \int_{0}^{T} \bar{\eta}_{i}(t) d W_{i}^{P}(t)-\frac{1}{2} \sum_{i=1}^{4} \int_{0}^{T} \bar{\eta}_{i}^{2}(t) d t\right]
$$

Under the forward martingale measure, $Q$, we can write

$$
\frac{d Z_{f}(t, T)}{Z_{f}(t, T)}=\sum_{i=1}^{4}\left[a_{f i}(t, T)+\delta_{d i}(t)\right] d W_{i}^{Q}(t)
$$

It is very intuitive that the drift term is depended on four return rates of these three assets, plus the foreign liquidity premium, $b_{f}(t, T)$. The domestic interest rate is negatively related to the rate of return of $Z_{f}(T, T)$. The instantaneous standard deviation of $Z_{f}(t, T)$, $\sum_{i=1}^{4}\left[a_{f i}(t, T)+\delta_{d i}(t)\right] d t$, is the same with the one of $P_{f}^{*}(T, T)$. Consider an European call on spot exchange rate with exercise price $X$ and expiration date $T$,

Let $\widetilde{E}$ denote expectation with respect to the forward martingale measure $Q$.

$$
C(0, T, K)=\widetilde{E}\left[\max \left(\frac{S_{T}-X}{B_{d}(T)}, 0\right)\right] .
$$

where

$$
B_{d}(T)=\exp \left[\int_{0}^{T} r_{d}(u) d u\right]
$$

$$
=\frac{1}{P_{d}(0, T)} \exp
$$$$
\left[-\frac{1}{2} \sum_{i=1}^{2} \int_{0}^{T} a_{d i}^{2}(v, T) d v+\sum_{i=1}^{2} \int_{0}^{T} a_{d i}(v, T) d \tilde{W}_{i}(v)\right]
$$

It is worth noting that the call value at maturity is discounted by domestic money account instead of risk-free discount bond.

By the definition,

$$
Z_{f}(t, T)=\frac{P_{f}(t, T) S_{d}(t)}{B_{d}(t)}=\frac{P_{f}^{*}(t, T)}{B_{d}(t)}
$$

$$
\because P_{f}(T, T)=1, \quad Z_{f}(T, T)=\frac{S_{d}(T)}{B_{d}(T)},
$$

$$
\begin{aligned}
& \text { we can represent the currency call as } \\
& \widetilde{E}\left[\max \left(Z_{f}(T, T)-\frac{X}{B_{d}(T)}, 0\right)\right]
\end{aligned}
$$$$
C(0, T, K)=\widetilde{E}\left[\max \left(Z_{f}(T, T)-\frac{X}{B_{d}(T)}, 0\right)\right]
$$

$$
\begin{aligned}
=\tilde{E} & \left\{Z _ { f } ( 0 , T ) \operatorname { e x p } \left(\left[\begin{array}{l}
{\left[\sum_{i=1}^{4} \int_{0}^{T}\left[a_{f i}(t, T)+\delta_{d i}(t)\right] d \tilde{W}_{i}(t)\right]} \\
-\frac{1}{2} \sum_{i=1}^{4} \int_{0}^{T}\left[a_{f i}(v, T)+\delta_{d i}(v)\right]^{2} d v
\end{array}\right)\right.\right. \\
& -X P_{d}(0, T) \exp \\
& {\left.\left[-\frac{1}{2} \sum_{i=1}^{2} \int_{0}^{t} a_{d i}^{2}(v, t) d v+\sum_{i=1}^{2} \int_{0}^{t} a_{d i}(v, t) d \tilde{W}_{i}(v)\right]\right\} }
\end{aligned}
$$

For simplicity, we can present the call as

$C(0, T, X)=P_{f}(0, T) S_{0} N(h)-X P_{d}(0, T) N(h-\zeta)$

where

$$
\begin{gathered}
h=\frac{\ln \left(\frac{P_{f}(0, T) S_{0}}{X P_{d}(0, T)}+\frac{1}{2} \zeta^{2}\right)}{\zeta} \\
\zeta^{2}=\operatorname{var}\left[\sum_{i=1}^{4} \int_{0}^{T}\left[a_{f i}(v, T)+\delta_{d i}(v)-a_{d i}(v, T)\right] d \widetilde{W}_{i}(v)\right] \\
=\sum_{i=1}^{4} \int_{0}^{T}\left[a_{f i}(v, T)+\delta_{d i}(v)-a_{d i}(v, T)\right]^{2} d v
\end{gathered}
$$

The complete derivation process can be seen in Amin and 
Jarrow (1991).

\subsection{Currency Option under Extended Normal Distribution with Two Stochastic Interest Rates}

To display the features of skewness and kurtosis, the log prices of exchange rate follow the proposed distribution probability that is constructed by $\mathrm{Ki}$, Choi, Chang, and Lee (2005). In this sub-section, the general closed-form function is described in detail. Consider an European call option on spot exchange rate with strike price $X$ and expiration date $T$.

$$
\begin{aligned}
& C(0, T, X)=\widetilde{E}\left[\max \left(\frac{S_{T}-X}{B_{d}(T)}, 0\right)\right] \\
& =\widetilde{E}\left[\max \left(Z_{f}(T, T)-\frac{X}{B_{d}(T)}, 0\right)\right]
\end{aligned}
$$

Consider the expected value of the currency option payoff at the maturity under extended normal distribution:

$$
\begin{gathered}
\widetilde{E}\left[\max \left(Z_{f}(T, T)-\frac{X}{B_{d}(T)}, 0\right)\right] \\
=\left(1+\frac{\xi s^{3}}{6}\right) \int_{\frac{\log \left(X / B_{d}(T)\right)-m}{s}}^{\infty} \exp (s y+m) \ell_{k}(y) d y \\
-\frac{X}{B_{d}(T)} \int_{\frac{\log \left(X / B_{d}(T)\right)-m}{s}}^{\infty} \ell_{k}(y) d y \\
+\frac{\xi}{6}\left\{s \frac{X}{B_{d}(T)} \ell_{k}^{\prime}\left(\frac{m-\log \left(X / B_{d}(T)\right)}{s}\right)\right. \\
\left.+s^{2} \frac{X}{B_{d}(T)} \ell_{k}\left(\frac{m-\log \left(X / B_{d}(T)\right)}{s}\right)\right\}
\end{gathered}
$$

The detail derivation is in Appendix A.

After converting the original underlying asset currency price into $Z_{f}(t, T)$, according to the Eq. (2.2.8), we have

$$
Z_{f}(t, T)=\frac{P_{f}(t, T) S_{t}}{B_{d}(t)}=\frac{P_{f}^{*}(t, T)}{B_{d}(t)}
$$

The stochastic process of $Z_{f}(t, T)$ is

$$
\begin{aligned}
& \frac{d Z_{f}(t, T)}{Z_{f}(t, T)}=\left[r_{f}(t)+b_{f}(t, T)+\mu_{d}(t)-r_{d}(t)\right] d t \\
& +\sum_{i=1}^{4}\left[a_{f i}(t, T)+\delta_{d i}(t)\right] d W_{i}(t)
\end{aligned}
$$

$$
=\beta_{f}(t, T) d t+\sum_{i=1}^{4}\left[a_{f i}(t, T)+\delta_{d i}(t)\right] d \mathrm{~W}_{i}(t)
$$

For

simplicity,

$\beta_{f}(t, T)=\left[r_{f}(t)+b_{f}(t, T)+\mu_{d}(t)-r_{d}(t)\right]$

The expected value of $Z_{f}(T, T)$ under the new measure $Q$ is

$$
\begin{gathered}
\tilde{E}\left[Z_{f}(T, T)\right]=Z_{f}(0, T) \exp \left(-\frac{1}{2} \sum_{i=1}^{4} \int_{0}^{T} \sigma_{Z_{f i}}^{2}(v, T) d v\right) \\
* \exp \left(\frac{1}{2} \sum_{i=1}^{4} \int_{0}^{T} \sigma_{Z_{f i}}^{2}(v, T) d v\right) \\
=Z_{f}(0, T)
\end{gathered}
$$

The detail derivation is in Appendix B.

Definition 2: The mean of underlying asset $Z_{f}(T, T)$ under the risk-neutral measure is

$$
\begin{gathered}
m=\log \left(Z_{f}(0, T)\right)-\log \left\{\left(1+\frac{\xi s^{3}}{6}\right)\right. \\
\left.\left[p e^{\alpha^{2} s^{2} / 2}+(1-p) e^{\beta^{2} s^{2} / 2}\right]\right\} \\
=\log \left(Z_{f}(0, T)\right)-\log (A+B)-\log \left(1+\frac{\xi s^{3}}{6}\right)
\end{gathered}
$$

$$
A=p e^{\alpha^{2} s^{2} / 2} \quad B=(1-p) e^{\beta^{2} s^{2} / 2}
$$

After replacing with

$$
\begin{aligned}
& \log \left(Z_{f}(0, T)\right)-\log (A+B)-\log \left(1+\frac{\xi^{3}}{6}\right) \\
& \widetilde{E}\left\{\max \left(Z_{f}(T, T)-\frac{X}{B_{d}(T)}, 0\right)\right\} \\
& \quad=P_{f}(0, T) S_{d}(0)\left[\frac{A}{A+B} N\left(d_{1}\right)+\frac{B}{A+B} N\left(d_{2}\right)\right] \\
& \quad-\frac{X}{B_{d}(T)}\left[p N\left(d_{3}\right)+(1-p) N\left(d_{4}\right)\right] \\
& +\frac{\xi s}{6} \frac{X}{B_{d}(T)}\left[\frac{p}{\alpha}\left(s-\frac{d_{3}}{\alpha}\right) n\left(d_{3}\right)+\frac{1-p}{\beta}\left(s-\frac{d_{4}}{\beta}\right) n\left(d_{4}\right)\right]
\end{aligned}
$$

where

$$
\begin{aligned}
& d_{1}=\frac{m+\alpha^{2} s^{2}-\log \left(X / B_{d}(T)\right)}{\alpha s} \\
& d_{2}=\frac{m+\beta^{2} s^{2}-\log \left(X / B_{d}(T)\right)}{\beta s}
\end{aligned}
$$




$$
\begin{aligned}
& d_{3}=\frac{m-\log \left(X / B_{d}(T)\right)}{\alpha s} \\
& d_{4}=\frac{m-\log \left(X / B_{d}(T)\right)}{\beta s}
\end{aligned}
$$

\subsection{Pricing Currency Option under CIR Term Structure Model}

In order to derive the price processes of risk-free discount bonds, the dynamic processes of the three state variables, the domestic risk-free interest rate $r_{d}$ and the foreign risk-free interest rate $r_{f}$ are shown as

$$
\begin{gathered}
d r_{d}=\left(k_{r} \theta_{r}-k_{r} r_{d}-\lambda_{r} r_{d}\right) d t+\sigma_{r_{d}} \sqrt{r_{d}} d Z_{r}^{P} \\
d r_{f}=\left(k_{f} \theta_{f}-k_{f} r_{f}-\lambda_{f} r_{f}\right) d t+\sigma_{r_{f}} \sqrt{r_{f}} d Z_{f}^{P}
\end{gathered}
$$

where $r$ is the borrowing and lending interest rate, $\sigma_{r}$ is the standard deviation of interest rate, $\theta$ is the long-term value of interest rate, $k$ is the parameter determining the speed of adjustment, $\lambda=\operatorname{cov}(d r, d w)$, the covariance of the interest rate and the wealth, and $\gamma \equiv\left((k+\lambda)^{2}+2 \sigma_{r}^{2}\right)^{1 / 2} \cdot k$ and $\theta$ have to be positive because the random interest rate is considered to incline to long-term value and the nominal interest would not be a negative value. Another limitation for these parameters is $2 k \theta \geq \sigma_{r}^{2}$ to guarantee the interest rate not to toward zero.

The exchange rate price process is the same as Dong, $\mathrm{Yu}$, Chan and Chung (2005) do.

$$
\frac{d S_{t}}{S_{t}}=\left(r_{d}-r_{f}\right) d t+\sigma_{s} \sqrt{\frac{r_{d}}{r_{f}}} d Z_{r}^{P}
$$

These three processes are not pairwise independent. Based on Monetarism, any currency price is determined by two interest rates. Besides, the drift term of them are correlated. Stochastic processes tend to exhibit mean-reverting, $k_{r}$ and $k_{f}$ are the seed of adjustment for domestic and foreign interest rates. In other words, the larger $k$, the more rapidly interest rate level comes back to the mean level $\left(\theta_{r}, \theta_{f}\right)$.

The instantaneous variance of spot exchange rate doesn't remain unchanged due to the fluctuant interest rates.

$$
\operatorname{Var}\left(\frac{d S_{t}}{S_{t}}\right)=\left(\sigma_{s} \sqrt{\frac{r_{d}}{r_{f}}}\right)^{2} d t
$$

Nevertheless, it is generally accepted that the phenomenon of mean reversion doesn't exist in nominal exchange rate. The mean reversion occurs in the real exchange rate since absolute purchasing power parity (PPP) might hold in the long run. This is because exchange rate can't return to an average level during 2 to 3 years of the option maturity. In order to acquire the computation results, CIR structure term structure model is applied.

Assumption Both domestic and foreign default-free discount bonds follow CIR bond process

$$
\begin{aligned}
& P_{d}(t, T)=A_{d}(t, T) e^{-B_{d}(t, T) r_{d}(t)} \\
& P_{f}(t, T)=A_{f}(t, T) e^{-B_{f}(t, T) r_{f}(t)}
\end{aligned}
$$

where

$$
\begin{aligned}
& \gamma_{k} \equiv\left[(k+\lambda)^{2}+2 \sigma^{2}\right]^{1 / 2} \quad k \in[d, f] \\
& A_{d}(t, T)= \\
&=\left(\frac{2 \gamma_{d} \exp ^{\left[\left(k_{d}+\lambda_{d}+\gamma_{d}\right)(T-t) / 2\right]}}{\left(\gamma_{d}+k_{d}+\lambda_{d}\right)\left(\exp ^{\gamma_{d}(T-t)}-1\right)+2 \gamma_{d}}\right)^{2 k_{d} \theta_{d} / \sigma_{r_{d}}^{2}} \\
& B_{d}(t, T)= \\
&=\left(\frac{2\left(\exp ^{\gamma_{d}(T-t)}-1\right)}{\left(\gamma_{d}+k_{d}+\lambda_{d}\right)\left(\exp ^{\gamma_{d}(T-t)}-1\right)+2 \gamma_{d}}\right) \\
& A_{f}(t, T)= \\
&=\left(\frac{2 \gamma_{d} \exp ^{\left[\left(k_{f}+\lambda_{f}+\gamma_{f}\right)(T-t) / 2\right]}}{\left(\gamma_{f}+k_{f}+\lambda_{f}\right)\left(\exp ^{\gamma_{f}(T-t)}-1\right)+2 \gamma_{f}}\right)^{2 k_{f} \theta_{f}} / \sigma_{r_{f}^{2}}^{2} \\
& B_{f}(t, T)= \\
&=\left(\frac{2\left(\exp ^{\gamma_{f}(T-t)}-1\right)}{\left(\gamma_{f}+k_{f}+\lambda_{f}\right)\left(\exp ^{\gamma_{f}(T-t)}-1\right)+2 \gamma_{f}}\right)
\end{aligned}
$$

The stochastic processes for domestic and foreign bonds

$$
\begin{gathered}
\frac{d P_{k}(t, T)}{P_{k}(t, T)}=r_{k}\left[1-\lambda_{k} B_{k}(t, T)\right] d t-B_{k}(t, T) \sigma_{r_{k}} d Z_{k} \\
k \in[d, f]
\end{gathered}
$$

The instantaneous variances of the two discount bonds are

$\operatorname{Var}\left(\frac{d P_{d}(t, T)}{P_{d}(t, T)}\right)=\left(B_{d}(t, T) \sigma_{r_{d}}\right)^{2} d t$

$$
=\left[\left(\frac{2\left(\exp ^{\gamma_{d}(T-t)}-1\right)}{\left(\gamma_{d}+k_{d}+\lambda_{d}\right)\left(\exp ^{\gamma_{d}(T-t)}-1\right)+2 \gamma_{d}}\right) \cdot \sigma_{r_{d}}\right]^{2} d t
$$




$$
\begin{aligned}
& \operatorname{Var}\left(\frac{d P_{f}(t, T)}{P_{f}(t, T)}\right)=\left(B_{f}(t, T) \sigma_{r_{f}}\right)^{2} d t \\
& =\left[\left(\frac{2\left(\exp ^{\gamma_{f}(T-t)}-1\right)}{\left(\gamma_{f}+k_{f}+\lambda_{f}\right)\left(\exp ^{\gamma_{f}(T-t)}-1\right)+2 \gamma_{f}}\right) \cdot \sigma_{r_{f}}\right]^{2} d t
\end{aligned}
$$

Consider a closed-form formula (2.3.4) for a currency call under CIR interest term structure and extended normal distribution:

$$
\begin{aligned}
& \widetilde{E}\left\{\max \left(Z_{f}(T, T)-\frac{X}{B_{d}(T)}, 0\right)\right\} \\
& =P_{f}(0, T) S_{0}\left[\frac{A}{A+B} N\left(d_{1}\right)+\frac{B}{A+B} N\left(d_{2}\right)\right]- \\
& \frac{X}{B_{d}(T)}\left[p N\left(d_{3}\right)+(1-p) N\left(d_{4}\right)\right] \\
& +\frac{\xi s}{6} \frac{X}{B_{d}(T)}\left[\frac{p}{\alpha}\left(s-\frac{d_{3}}{\alpha}\right) n\left(d_{3}\right)+\frac{1-p}{\beta}\left(s-\frac{d_{4}}{\beta}\right) n\left(d_{4}\right)\right] \\
& m=\log \left(Z_{f}(0, T)\right)-\log (A+B)-\log \left(1+\frac{\xi s^{3}}{6}\right)
\end{aligned}
$$

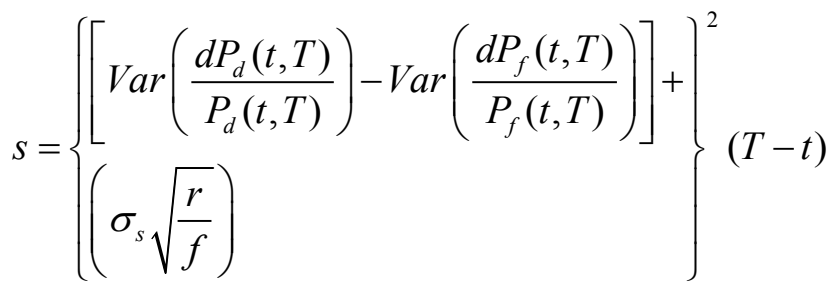

$$
\begin{aligned}
& \begin{array}{l}
d_{1}=\frac{m+\alpha^{2} s^{2}-\log \left(X / B_{d}(T)\right)}{\alpha s} \\
d_{2}=\frac{m+\beta^{2} s^{2}-\log \left(X / B_{d}(T)\right)}{\beta s}
\end{array} \\
& d_{3}=d_{1}-\alpha s \\
& d_{4}=d_{2}-\beta s
\end{aligned}
$$

\section{Numerical Analysis}

\subsection{The Currency Option Value under CIR Term Structure}

To incorporate stochastic interest rates into Black-Scholes option pricing model, CIR term structure is put into the general formula proposed by Amin and Jarrow (1991) to show some call prices calculated by the proposed model. The call prices we acquire different from the traditional
Black-Scholes' model is attributed to the fact that both of the domestic and the foreign interest rates are floating and influenced by many factor, such as risk aversion, preference about the timing of consumption, and investment alternatives, etc. It is worth noting that the probability density of the underlying asset is normal distribution and assumes there doesn't exit skewness and kurtosis. We set both current value of the domestic and the foreign interest rates are 5\% $\left(r_{d_{0}}=0.05, r_{f_{0}}=0.05\right)$ and think they would return to $7 \%$ ( $\left.\theta_{r}=0.07, \theta_{f}=0.07\right)$ in the long run. The underlying asset currency price is determined by the two countries' interest rates and the instantaneous variance of the exchange rate. Hence, the variation of the currency price would incorporate all factors which appear in the interest rates' processes.

Table 1 mainly displays the results of Amin and Jarrow's model (1991) and extended normal distribution model with kurtosis 3 and skewness 0 . We can acquire the completely identical values as long as extended normal distribution converges to the normal distribution. For simplicity, we represent Amin and Jarrow's model (1991) as A-J model and extended normal distribution model as END in Table 1.

We set other parameters as follows, the initial value of the domestic and foreign interest rates are $r_{d_{0}}=5 \%, r_{f_{0}}=5 \%$, the current price of foreign currency $S_{0}=30$, time to maturity $T-t=0.5$ and 1 year, the volatility of currency price, the domestic and the foreign interest rates are $\sigma_{s}=0.25, \sigma_{r_{d}}=0.1$, and $\sigma_{r_{f}}=0.15$. Assume the speed of adjustments for the domestic and foreign interest rates are $k_{d}=0.1, k_{f}=0.1$ and the risk premiums are $\lambda_{d}=0.01$, and $\lambda_{f}=0.01$.

\subsection{Pricing Currency Call Price with Various Kurtosis and Skewness under CIR Term Structure}

After stretching the traditional Black-Sholes' model to stochastic interest rates, the features of the kurtosis and skewness are taken into account in this section. The following three tables (Table 2, Table 3 and Table 4) would illustrate the results of extended normal currency call pricing model under CIR interest term structure with the kurtosis varied but the skewness fixed at zero, and with the skewness varied but the kurtosis fixed at 3 , respectively.

The currency option price decreases with increasing kurtosis due to that the probability of in-the-money is lower based on higher kurtosis if the strike price higher than the mean of the probability distribution. However the relationship doesn't exist only in some deep out of-money and high kurtosis cases when the initial value of domestic interest rate is smaller than that of foreign interest rate. Furthermore, the currency option price decreases with raising skewness since the probability of in-the-money is lower with higher skewness if the strike price higher than the mean of the real probability distribution.

The major topics we discuss in this paper are stochastic 
interest rates and non-normal distribution, we would observe the currency call prices by changing the initial values and the long-run average level of the two interest rates but fixing the other parameter like adjustment $\operatorname{speed}\left(k_{d}=0.1, k_{f}=0.1\right)$, risk premium $\left(\lambda_{d}=0.01, \lambda_{f}=0.01\right)$, and the standard deviation of the two interest rates and currency price.

Later we would discuss how these important factors work upon the currency call price by drawing. For instance, if we set the initial value of the domestic interest rate larger than that of the foreign interest rate, how the call option value changes. Besides, we would emphasize on how the level of skewness and kurtosis influence the value of currency call. Is the currency call overpriced or under-priced when the underlying asset's distribution with kurtosis and skewness? And what role does exercise price play when pricing a currency call under extended normal distribution?

Table 1. Amin and Jarrow Model (A-J model) vs. Extended Normal Distribution Model (END)

\begin{tabular}{|c|c|c|c|c|}
\hline & A-J model & END & A-J model & END \\
\hline Strike Price & \multicolumn{2}{|c|}{$\mathrm{T}-\mathrm{t}=0.5$} & \multicolumn{2}{|c|}{$\mathrm{T}-\mathrm{t}=1$} \\
\hline 15 & 14.2750 & 14.2750 & 13.7572 & 13.7572 \\
\hline 16 & 13.3457 & 13.3457 & 12.8955 & 12.8955 \\
\hline 17 & 12.4174 & 12.4174 & 12.0455 & 12.0455 \\
\hline 28 & 3.4550 & 3.4550 & 4.5003 & 4.5003 \\
\hline 29 & 2.9133 & 2.9133 & 4.0363 & 4.0363 \\
\hline 31 & 2.0155 & 2.0155 & 3.2221 & 3.2221 \\
\hline 32 & 1.6546 & 1.6546 & 2.8686 & 2.8686 \\
\hline 43 & 0.1186 & 0.1186 & 0.7103 & 0.7103 \\
\hline 44 & 0.0903 & 0.0903 & 0.6206 & 0.6206 \\
\hline 45 & 0.0685 & 0.0685 & 0.5416 & 0.5416 \\
\hline
\end{tabular}

The initial interest rates of the domestic and the foreign are $r_{d_{0}}=0.07, r_{f_{0}}=0.07$. The other parameters are presented below.

\begin{tabular}{|c|c|c|c|c|}
\hline & A-J model & END & A-J model & END \\
\hline & \multicolumn{2}{|c|}{$\mathrm{T}-\mathrm{t}=0.5$} & \multicolumn{2}{|c|}{$\mathrm{T}-\mathrm{t}=1$} \\
\hline 15 & 14.2785 & 14.2785 & 14.0021 & 14.0021 \\
\hline 16 & 13.3489 & 13.3489 & 13.0987 & 13.0987 \\
\hline 17 & 12.1963 & 12.1963 & 11.6724 & 11.6724 \\
\hline 28 & 3.4465 & 3.4465 & 4.4168 & 4.4168 \\
\hline 29 & 2.9120 & 2.9120 & 3.9669 & 3.9669 \\
\hline 30 & 2.4380 & 2.4380 & 3.5537 & 3.5537 \\
\hline 31 & 2.0230 & 2.0230 & 3.1756 & 3.1756 \\
\hline 32 & 1.6643 & 1.6643 & 2.8312 & 2.8312 \\
\hline 43 & 0.1222 & 0.1222 & 0.7118 & 0.7118 \\
\hline 44 & 0.0933 & 0.0933 & 0.0933 & 0.0933 \\
\hline 45 & 0.0709 & 0.0709 & 0.0709 & 0.0709 \\
\hline
\end{tabular}

Table 2. The Currency Call Price with Higher Initial Foreign Interest Rate $\left(r_{d_{0}}=0.05, r_{f_{0}}=0.07\right)$ and Various Kurtosis and Skewness

\begin{tabular}{|c|c|c|c|c|c|c|c|c|c|c|c|}
\hline \multicolumn{12}{|c|}{ Exercise Price } \\
\hline & 25 & 26 & 27 & 28 & 29 & 30 & 31 & 32 & 33 & 34 & 35 \\
\hline \multicolumn{12}{|l|}{ Kurt } \\
\hline $3 *$ & 4.6967 & 3.9732 & 3.3149 & 2.7274 & 2.2131 & 1.7713 & 1.3990 & 1.0908 & 0.8400 & 0.6392 & 0.4810 \\
\hline 4 & 4.6830 & 3.9377 & 3.2585 & 2.6556 & 2.1346 & 1.6962 & 1.3362 & 1.0467 & 0.8178 & 0.6389 & 0.5000 \\
\hline 5 & 4.6728 & 3.9068 & 3.2066 & 2.5873 & 2.0592 & 1.6244 & 1.2776 & 1.0076 & 0.8004 & 0.6420 & 0.5201 \\
\hline 6 & 4.6646 & 3.8805 & 3.1605 & 2.5254 & 1.9900 & 1.5589 & 1.2252 & 0.9739 & 0.7868 & 0.6462 & 0.5384 \\
\hline \multicolumn{12}{|l|}{ Skew } \\
\hline-0.4 & 4.7487 & 4.0170 & 3.3433 & 2.7345 & 2.1955 & 1.7286 & 1.3331 & 1.0060 & 0.7418 & 0.5335 & 0.3733 \\
\hline-0.2 & 4.7227 & 3.9951 & 3.3291 & 2.7309 & 2.2042 & 1.7499 & 1.3660 & 1.0483 & 0.7909 & 0.5864 & 0.4272 \\
\hline $0 *$ & 4.6967 & 3.9732 & 3.3149 & 2.7274 & 2.2131 & 1.7713 & 1.3990 & 1.0908 & 0.8400 & 0.6392 & 0.4810 \\
\hline 0.2 & 4.6708 & 3.9513 & 3.3008 & 2.7240 & 2.2220 & 1.7929 & 1.4321 & 1.1333 & 0.8891 & 0.6921 & 0.5348 \\
\hline 0.4 & 4.6449 & 3.9295 & 3.2868 & 2.7207 & 2.2311 & 1.8146 & 1.4653 & 1.1759 & 0.9383 & 0.7450 & 0.5886 \\
\hline
\end{tabular}

The parameters are set as

$S_{0}=30, r_{d_{0}}=0.05, r_{f_{0}}=0.07, k_{r}=0.1, k_{f}=0.1, \theta_{r}=0.07, \theta_{f}=0.07, \lambda_{r}=0.01, \lambda_{f}=0.01, \sigma=0.25, \sigma_{r}=0.1, \sigma_{f}=0.15$ 
The call price maintains negatively correlated with kurtosis except that kurtosis reaching 6 when the strike price is 34 . The price is 0.6389 when kurtosis is 5 but rises to 0.6420 as kurtosis reaching to 5 . There is a division between $X=28$ and $X=29$. The call price is positively related with the skewness when strike price is over than 29 or equals 29 ; negatively related with the skewness when the strike price is less than or equals 28 .

* When kurtosis is 3 and skewness is 0 , extended normal distribution is reduced to the normal distribution and the results equal to the values calculated by Amin and Jarrow's (1991).

Table 3. The Currency Call Price with the Same Initial Interest Rate $\left(r_{d_{0}}=0.05, r_{f_{0}}=0.05\right)$ and Various Kurtosis and Skewness

\begin{tabular}{cccccccccccc}
\hline & \multicolumn{10}{c}{ Exercise Price } \\
\hline & 25 & 26 & 27 & 28 & 29 & 30 & 31 & 32 & 33 & 34 & 35 \\
\hline Kurt & & & & & & & & & & \\
$\mathbf{3}^{*}$ & 5.4443 & 4.7235 & 4.0591 & 3.4551 & 2.9133 & 2.4340 & 2.0155 & 1.6546 & 1.3472 & 1.0882 & 0.8725 \\
$\mathbf{4}$ & 5.4251 & 4.6825 & 3.9969 & 3.3758 & 2.8239 & 2.3427 & 1.9307 & 1.5836 & 1.2950 & 1.0578 & 0.8643 \\
$\mathbf{5}$ & 5.4102 & 4.6468 & 3.9399 & 3.3010 & 2.7382 & 2.2551 & 1.8502 & 1.5177 & 1.2488 & 1.0333 & 0.8610 \\
$\mathbf{6}$ & 5.3981 & 4.6164 & 3.8897 & 3.2334 & 2.6598 & 2.1747 & 1.7770 & 1.4590 & 1.2089 & 1.0136 & 0.8602 \\
\hline & & & & & & & & & & \\
\hline Skew & & & & & & & & & & \\
$\mathbf{- 0 . 4}$ & 5.5011 & 4.7718 & 4.0923 & 3.4679 & 2.9021 & 2.3972 & 1.9536 & 1.5699 & 1.2433 & 0.9698 & 0.7445 \\
$\mathbf{- 0 . 2}$ & 5.4727 & 4.7476 & 4.0757 & 3.4614 & 2.9076 & 2.4155 & 1.9844 & 1.6122 & 1.2952 & 1.0290 & 0.8085 \\
$\mathbf{0} *$ & 5.4443 & 4.7235 & 4.0591 & 3.4551 & 2.9133 & 2.4340 & 2.0155 & 1.6546 & 1.3472 & 1.0882 & 0.8725 \\
$\mathbf{0 . 2}$ & 5.4160 & 4.6996 & 4.0428 & 3.4489 & 2.9192 & 2.4528 & 2.0468 & 1.6972 & 1.3993 & 1.1475 & 0.9365 \\
$\mathbf{0 . 4}$ & 5.3877 & 4.6757 & 4.0265 & 3.4430 & 2.9253 & 2.4717 & 2.0782 & 1.7400 & 1.4515 & 1.2069 & 1.0006 \\
\hline
\end{tabular}

The parameters are set as

$S_{0}=30, r_{d_{0}}=0.05, r_{f_{0}}=0.05, k_{r}=0.1, k_{f}=0.1, \theta_{r}=0.07, \theta_{f}=0.07, \lambda_{r}=0.01, \lambda_{f}=0.01, \sigma=0.25, \sigma_{r}=0.1, \sigma_{f}=0.15$

The call price is decreasing while the kurtosis is getting larger. We can conclude there is a negative relationship between the price of call option and the kurtosis value. The strike price 29 can also be deemed as a division as last case. As compared with the last case, all of the call prices are much higher. Therefore, the higher initial domestic interest rate would generate higher currency price and more valuable currency call options.

* When kurtosis is 3 and skewness is 0 , extended normal distribution is reduced to the normal distribution and the results equal to the values calculated by Amin and Jarrow's (1991).

Table 4. The Currency Call Price with Initial Higher Interest Rate ( $\left.r_{d_{0}}=0.07, r_{f_{0}}=0.05\right)$ and Various Kurtosis and Skewness

\begin{tabular}{|c|c|c|c|c|c|c|c|c|c|c|c|}
\hline \multicolumn{12}{|c|}{ Exercise Price } \\
\hline & 25 & 26 & 27 & 28 & 29 & 30 & 31 & 32 & 33 & 34 & 35 \\
\hline \multicolumn{12}{|l|}{ Kurt } \\
\hline 3* & 6.1780 & 5.4809 & 4.8310 & 4.2311 & 3.6826 & 3.1859 & 2.7400 & 2.3434 & 1.9934 & 1.6870 & 1.4208 \\
\hline 4 & 6.1525 & 5.4341 & 4.7635 & 4.1460 & 3.5850 & 3.0823 & 2.6375 & 2.2486 & 1.9121 & 1.6236 & 1.3780 \\
\hline 5 & 6.1322 & 5.3935 & 4.7021 & 4.0662 & 3.4920 & 2.9828 & 2.5392 & 2.1588 & 1.8368 & 1.5668 & 1.3421 \\
\hline 6 & 6.1154 & 5.3588 & 4.6482 & 3.9946 & 3.4073 & 2.8917 & 2.4494 & 2.0775 & 1.7697 & 1.5178 & 1.3126 \\
\hline \multicolumn{12}{|l|}{ Skew } \\
\hline-0.4 & 6.2376 & 5.5315 & 4.8672 & 4.2482 & 3.6771 & 3.1556 & 2.6845 & 2.2633 & 1.8909 & 1.5649 & 1.2828 \\
\hline-0.2 & 6.2078 & 5.5061 & 4.8490 & 4.2395 & 3.6797 & 3.1706 & 2.7121 & 2.3032 & 1.9420 & 1.6259 & 1.3517 \\
\hline $0^{*}$ & 6.1780 & 5.4809 & 4.8310 & 4.2311 & 3.6826 & 3.1859 & 2.7400 & 2.3434 & 1.9934 & 1.6870 & 1.4208 \\
\hline 0.2 & 6.1483 & 5.4558 & 4.8132 & 4.2229 & 3.6858 & 3.2014 & 2.7682 & 2.3838 & 2.0450 & 1.7483 & 1.4900 \\
\hline 0.4 & 6.1187 & 5.4308 & 4.7956 & 4.2150 & 3.6893 & 3.2173 & 2.7968 & 2.4245 & 2.0969 & 1.8098 & 1.5593 \\
\hline
\end{tabular}

The parameters are set as

$S_{0}=30, r_{d_{0}}=0.05, r_{f_{0}}=0.07, k_{r}=0.1, k_{f}=0.1, \theta_{r}=0.07, \theta_{f}=0.07, \lambda_{r}=0.01, \lambda_{f}=0.01, \sigma=0.25, \sigma_{r}=0.1, \sigma_{f}=0.15$

In this case, the relationship between the call price and the kurtosis and between the call price and the skewness are the same with the last case. We set the greater initial value of the domestic interest rate than the foreign one. It is intuitive to comprehend that the higher initial domestic interest rate would go along with higher currency call price.

* When kurtosis is 3 and skewness is 0 , extended normal distribution is reduced to the normal distribution and the results equal to the values calculated by Amin and Jarrow's (1991). 


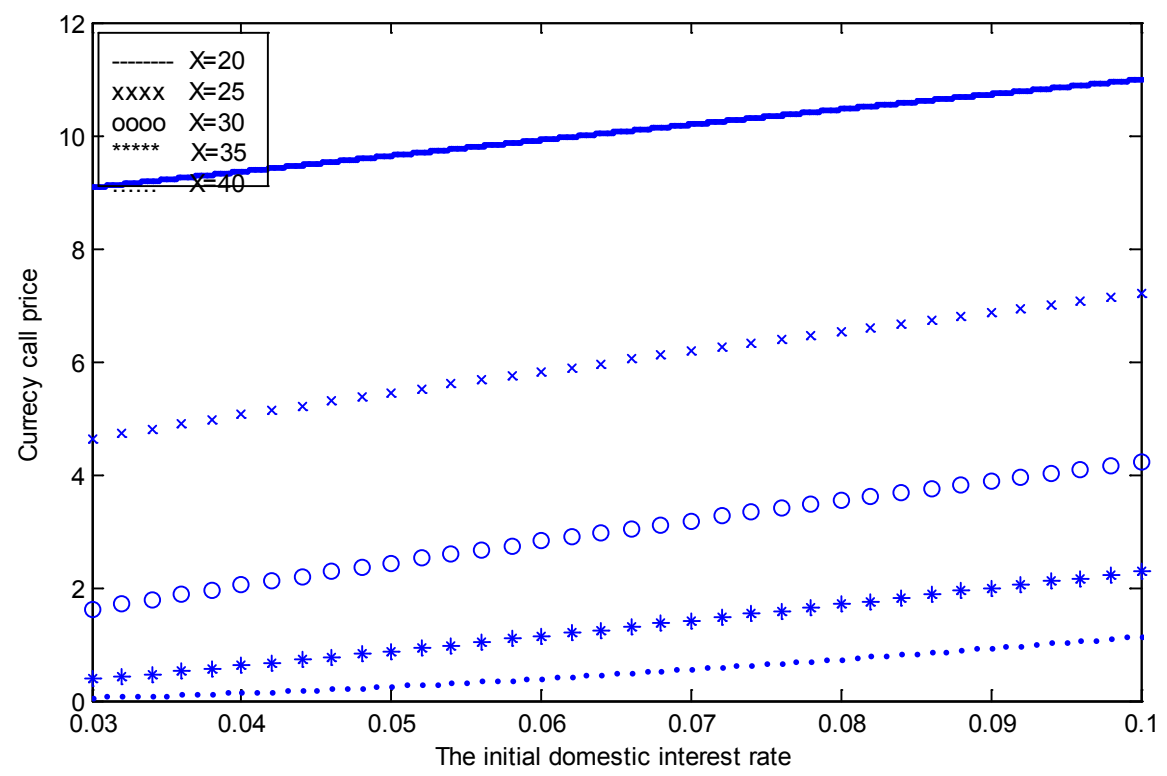

Figure 1. The Currency Call Price with Various Initial Domestic Interest Rate and Different Strike Price

Figure 1 is discussed the initial domestic interest rate's sensitivity to currency options when the initial value of the foreign interest rate is fixed at $r_{f_{0}}=5 \%$. We assume that the current price of foreign currency $S_{0}=30$, time to maturity $T-t=0.5$ year, the volatility of currency price, the domestic and the foreign interest rates are $\sigma_{s}=0.25, \sigma_{r_{d}}=0.1$, and $\sigma_{r_{f}}=0.15$, speed of adjustments for the domestic and foreign interest rates are $k_{d}=0.1, k_{f}=0.1$ and the risk premiums are $\lambda_{d}=0.01$, and $\lambda_{f}=0.01$.

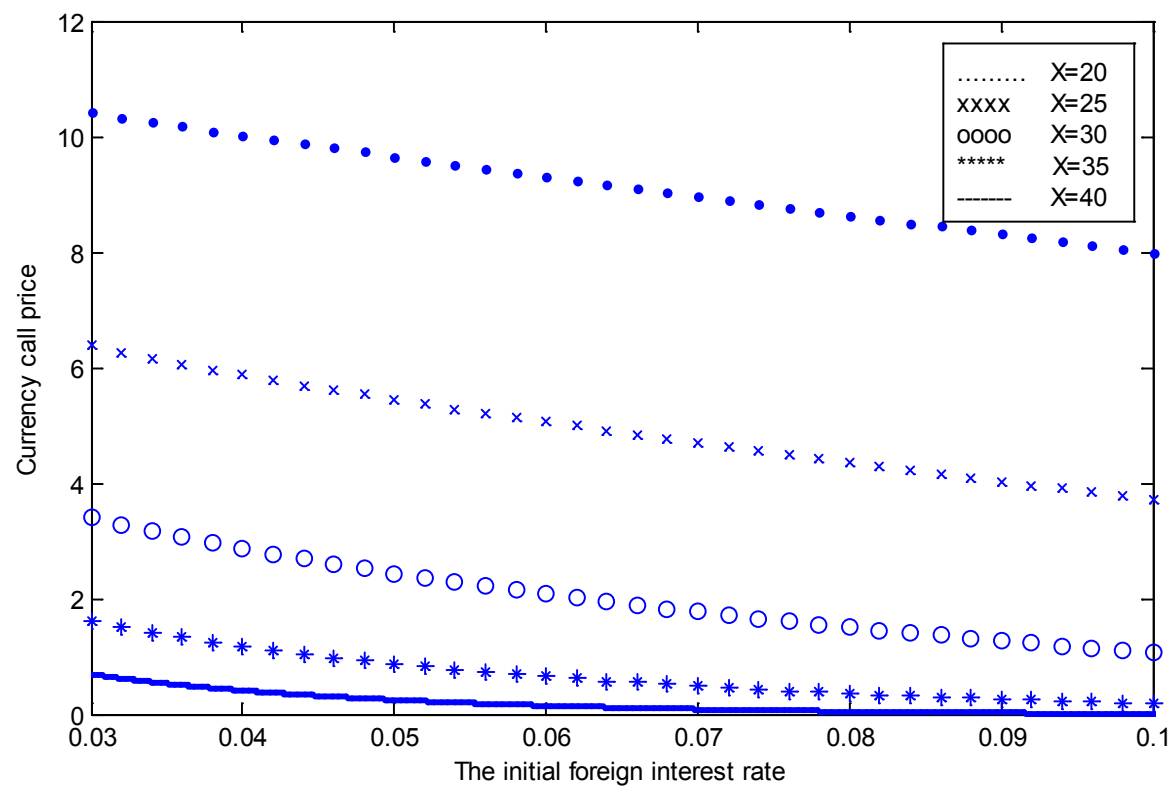

Figure 2. The Currency Call Price with Various Initial Foreign Interest Rate and Different Strike Price

Figure 2 is discussed the initial foreign interest rate's sensitivity to currency options when the initial value of the domestic interest rate is fixed at $r_{d_{0}}=5 \%$. We assume that the current price of foreign currency $S_{0}=30$, time to maturity
$T-t=0.5$ year, the volatility of currency price, the domestic and the foreign interest rates are $\sigma_{s}=0.25$, $\sigma_{r_{d}}=0.1, \quad$ and $\sigma_{r_{f}}=0.15$, speed of adjustments for the domestic and foreign interest rates are $k_{d}=0.1, k_{f}=0.1$ 
and the risk premiums are $\lambda_{d}=0.01$, and $\lambda_{f}=0.01$.

Figure 1 and Figure 2 demonstrate how the initial domestic and the foreign interest rates affect the value of currency price. It is easy to understand the domestic interest and the foreign interest rate have the opposite effect on the call price. Moreover, how these two different price is defined as the currency call option price under normal distribution minus the currency call option price under extended normal distribution with kurtosis 3.0, 4.0, 5.0, and 6.0 and skewness $-0.4,-0.2,0,0.2$, and 0.4 respectively. The initial values of both interest rates are $5 \%$ and the mean values are $5 \%$ as well. The adjustment speeds are set to be 0.1 . The current price is 30 and the exercise price is from 20 to 40 (deep in-the money to deep out-of-the money).

Figure 3 shows price difference between the currency call under normal distribution and under extended normal distribution. We set other parameters as follows, the current price of foreign currency $S_{0}=30$, time to maturity $T-t=0.5$ year, the volatility of currency price, the domestic and the foreign interest rates are $\sigma_{s}=0.25$, $\sigma_{r_{d}}=0.1$, and $\sigma_{r_{f}}=0.15$. Assume the speed of adjustments for the domestic and foreign interest rates are $k_{d}=0.1$, $k_{f}=0.1$ and the risk premiums are $\lambda_{d}=0.01$, and $\lambda_{f}=0.01$.

It is easy to note the call prices calculated under extended normal distribution with the strike price 24 and 36 are very similar to the ones calculated under the normal distribution. The currency prices are undervalued compared with pricing under the non-normal distribution in the interval of strike price between 20 and 24 (deep in-the-money) and in the interval between 36 and 40 (deep out-of-money).

In contrast, the currency call price is overvalued when the strike price ranges from 24 to 36 and we can find the shape of this result is symmetric. The call options under the distribution density with higher kurtosis value are overpriced much more than with lower kurtosis value.

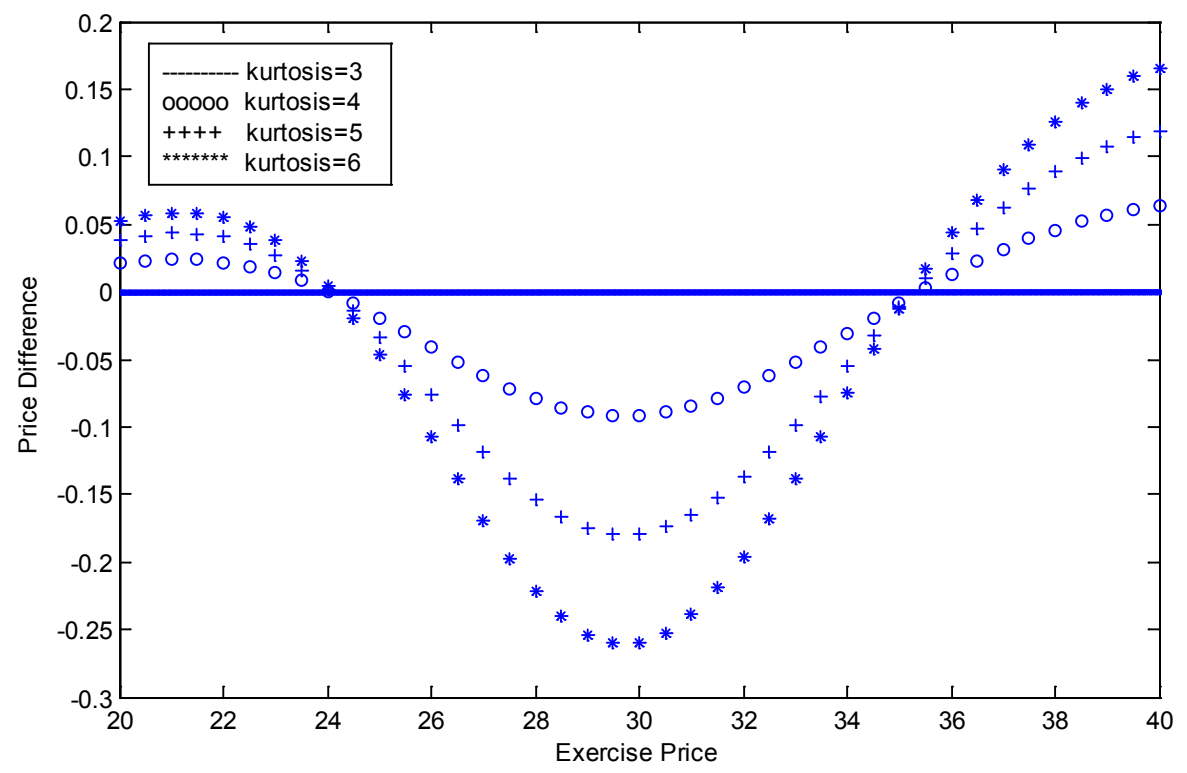

Figure 3. The Difference between the Call Price under Normal Distribution and under Extended Normal Distribution with Various Skewnesses 


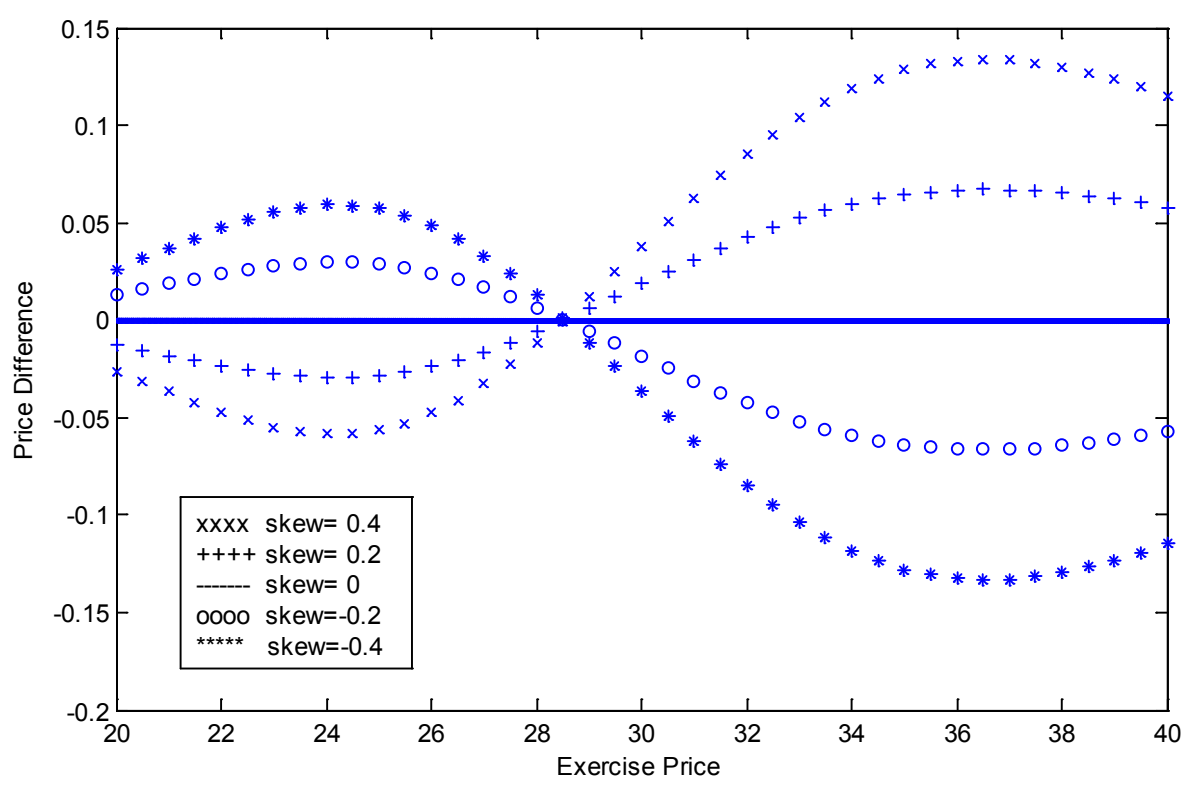

Figure 4. The Difference between the Call Price under Normal Distribution and under Extended Normal Distribution with Various Skewnesses

Figure 4 shows price difference between the currency call under normal distribution and under extended normal distribution. We set other parameters as follows, the current price of foreign currency $S_{0}=30$, time to maturity $T-t=0.5$ year, the volatility of currency price, the domestic and the foreign interest rates are $\sigma_{s}=0.25$, $\sigma_{r_{d}}=0.1$, and $\sigma_{r_{f}}=0.15$. Assume the speed of adjustments for the domestic and foreign interest rates are $k_{d}=0.1$, $k_{f}=0.1$ and the risk premiums are $\lambda_{d}=0.01$, and $\lambda_{f}=0.01$.

The currency call option appraised under extended normal distribution is completely the same as appraised under the normal distribution when the strike price is around 28.5.

The price different is closer to zero when the strike price in the interval of 26 to 32 . The price differences with positive and negative skewness are approaching towards opposite direction. The currency call price estimated under extended normal distribution with smaller skewness is undervalued much more than under the same probability distribution with larger skewness when strike price in the interval of 29 to 40 . On the other hand, compared to the ones calculated under the normal distribution in the interval of 20 to 29. Call options priced under extended normal distribution with positive skewness is undervalued.

\subsection{Value Comparison between Extended Model and the Monte Carlo Simulation}

Our pricing model is mainly worked to incorporate the pattern of stochastic interest rates; however, the instantaneous variance of the currency prices is assumed to be constant. Monte Carlo Simulation is one of most widely used numerical method to price option prices. The method solves a financial problem by simulating the prices of underlying assets over a certain period; consequently it is a very general but time-consuming approach. In this section, we would show the computation of Monte Carlo simulation to compare with the results of our proposed model. For the calculations presented, we suppose the current and the long-term level of interest rates are as follows. $r_{d_{0}}=0.05$, $r_{f_{0}}=0.05, \theta_{r}=0.05, \theta_{f}=0.05$, the standard deviation of the three variables $\sigma_{r_{d}}=0.1, \sigma_{r_{f}}=0.15, \sigma_{s}=0.25$.

Next we create 2000 sample paths and 2000 time steps for each of the domestic and the foreign risk-neutral interest rates. As a result, we can acquire the 2000 sample paths of the underlying asset. The mesh size consider contained on the order of 4,000,000 nodes. The call option price we present below is the mean of the 2000 sample paths and $95 \%$ confidence intervals of the option price. However, the most of prices simulated by Monte Carlo method is higher than the ones priced calculated by Amin and Jarrow's (1991) closed-form model (fixed volatility). The second column is presented the examples of the Monte Carlo method by setting the instantaneous standard deviation of currency price fixed. Theoretically, the values should be much closer to the ones computed by the closed-form solution because of the same assumption. The last one column is the results from our proposed model under CIR term structure model. 
Table 5. The Comparison among Monte Carlo (Stochastic Volatility), Monte Carlo (Constant Volatility) and Extended Normal Model.

\begin{tabular}{|c|c|c|c|c|c|c|c|}
\hline \multirow{3}{*}{ Strike Price } & \multicolumn{3}{|c|}{ Monte Carlo (Stochastic Volatility) } & \multicolumn{3}{|c|}{ Monte Carlo (Constant Volatility) } & \multirow{3}{*}{$\begin{array}{c}\begin{array}{c}\text { Extended Normal Model } \\
\text { (kurtosis }=3 \text {, skewness }=0, \\
\text { Constant Volatility) }\end{array} \\
\text { Price }\end{array}$} \\
\hline & \multirow[t]{2}{*}{ Price } & \multicolumn{2}{|c|}{ Confidence Interval } & \multirow[t]{2}{*}{ Price } & \multicolumn{2}{|c|}{ Confidence Interval } & \\
\hline & & $\mathrm{L}$ & $\mathrm{U}$ & & $\mathrm{L}$ & $\mathrm{U}$ & \\
\hline 16 & 14.8017 & 14.5533 & 15.0501 & 14.7758 & 14.5362 & 15.0155 & 13.3489 \\
\hline 17 & 13.8146 & 13.5537 & 14.0755 & 13.6185 & 13.3820 & 13.8551 & 12.4205 \\
\hline 18 & 12.8552 & 12.6018 & 13.1085 & 12.7328 & 12.4967 & 12.9689 & 11.4945 \\
\hline 19 & 11.7182 & 11.4696 & 11.9669 & 11.8188 & 11.5787 & 12.0589 & 10.5734 \\
\hline 20 & 10.8205 & 10.5680 & 11.0729 & 10.6809 & 10.4471 & 10.9147 & 9.6608 \\
\hline 28 & 4.0481 & 3.8392 & 4.2571 & 3.9309 & 3.7287 & 4.1330 & 3.4558 \\
\hline 29 & 3.2867 & 3.0897 & 3.4838 & 3.2301 & 3.0526 & 3.4076 & 2.9140 \\
\hline 30 & 2.8110 & 2.6221 & 2.9990 & 2.5790 & 2.4108 & 2.7473 & 2.4346 \\
\hline 31 & 2.3081 & 2.1330 & 2.4832 & 2.1603 & 2.0081 & 2.3124 & 2.0160 \\
\hline 32 & 1.8652 & 1.7020 & 2.0283 & 1.7121 & 1.5776 & 1.8466 & 1.6550 \\
\hline 41 & 0.2051 & 0.1498 & 0.2603 & 0.1458 & 0.1081 & 0.1835 & 0.2019 \\
\hline 42 & 0.2396 & 0.1647 & 0.3144 & 0.0801 & 0.0560 & 0.1402 & 0.1552 \\
\hline 43 & 0.1567 & 0.1118 & 0.2016 & 0.0794 & 0.0533 & 0.1341 & 0.1187 \\
\hline 44 & 0.0742 & 0.0479 & 0.1006 & 0.0783 & 0.0495 & 0.1071 & 0.0904 \\
\hline 45 & 0.0816 & 0.0519 & 0.1113 & 0.0383 & 0.0180 & 0.0586 & 0.0685 \\
\hline
\end{tabular}

Table 5 shows the computation results from Monte Carlo simulation (constant volatility), Monte Carlo simulation (stochastic volatility) and closed-form solution. The current stock price $S_{0}=30$, and three strike price intervals $(X=[15,20], X=[28,32], X=[40,45])$. Assume domestic and foreign risk-free rates are both $5 \%$, time to maturity is $T-t=0.5$ year. $\mathrm{L}$ and $\mathrm{U}$ represent the lower bound and upper bound for the $95 \%$ confidence interval for the normal distribution.

We can learn that Monte Carlo methods with stochastic volatility and without stochastic volatility provide similar outcomes when the option price is deep out-of-the money. Although the Monte Carlo simulation with the constant volatility doesn't result in the approximate value to the ones calculate by the closed-form solution, a half of outcomes from closed-form solution fall in the confidence interval which the simulation with fixed volatility offers. To improve the numerical performance by using the traditional Monte Carlo approach can be reformed to show the smaller interval and variances by variance reduction techniques or Quasi-Monte Carlo simulation.

\subsection{Research Findings}

It is widely discussed that the Black-Scholes formula which based on some ideal assumptions (volatility, interest rate are assumed to be constant) would lead the pricing results deviated from the actual market price. This is due to the reason that the actual market variables are not constants. Hence, the assumptions of the Black-Scholes' formula which based on constant volatility and interest rate and lead to stock returns follow the normal distribution should be revised. The proposed model use the extended normal distribution and CIR interest rate model to extend the Black-Scholes formula to become a more general formula which can capture the volatility smile effect that always existed in currency options and currency derivatives. The market participants can use the actual market data to calibrate the parameters of the proposed model and use the proposed model to price the currency options and derivatives accurately.

\section{Conclusions}

In this paper, we propose a closed-form formula to price currency option under stochastic interest rates and extended normal distribution. That is to say the risk-free interest rates of the domestic and the foreign vary with time. The dynamic processes of stochastic interest rates and foreign currency are developed by Amin and Jarrow (1991). However, without analyzing empirical data, it is too early to conclude with the pricing model we draw in the paper offers more accurate results than the traditional Black Scholes model does.

From the Monte Carlo simulation, we can figure out that option prices with stochastic volatility are higher than those with constant volatility. Second, the more underlying probability deviating from the normal distribution, the more deeply it brings about underpricing or overpricing.

CIR model is not the most precise and thorough one which depicts the variation of interest rate in the real economic world. There are still many other interest structure models which capture the state of interest in different viewpoints such as BDT model [Black, Derman and Toy(1990)] and HJM model [(Heath, Jarrow and Morton (1987)], etc. we have to change the interest term structure model based on the characteristics of the specific economic environment. Since we propose closed-form formula for pricing currency option with less restriction in theory, we look forward to enhancing the accuracy in currency option pricing. 


\section{Appendix A}

\section{Proof of Equation (4.1.2)}

Consider a European currency call option under extended normal distribution and stochastic interest rates

$$
C(T, T, X)=\max \left(S_{T}-X, 0\right) .
$$

The present value of the call option is

$$
\begin{aligned}
& C(0, T, X)=E\left[\max \left(\frac{S_{T}-X}{B_{d}(T)}, 0\right)\right] \\
& =E\left[\max \left(Z_{f}(T, T)-\frac{X}{B_{d}(T)}, 0\right)\right] \\
& \text { Normalizing: } \frac{\log Z_{f}(T, T)-m}{s}=y \Rightarrow Z_{f}(T, T)=\exp (s y+m) \\
& C(0, T, X)=E\left[\max \left(\frac{S_{T}-X}{B_{d}(T)}, 0\right)\right] \\
& =\int_{\frac{\log \left(X / B_{d}(T)\right)-m}{s}}^{\infty}\left[\exp (s y+m)-\frac{X}{B_{d}(T)}\right]\left[\ell_{k}(y)-\frac{\xi}{6} \ell_{k}^{\prime \prime \prime}(y)\right] d y \\
& =\int_{\frac{\log \left(X / B_{d}(T)\right)-m}{s}}^{\infty}\left[\exp (s y+m)-\frac{X}{B_{d}(T)}\right] \ell_{k}(y) d y-\int_{\frac{\log \left(X / B_{d}(T)\right)-m}{s}}^{\infty}\left[\exp (s y+m)-\frac{X}{B_{d}(T)}\right] \frac{\xi}{6} \ell_{k}^{\prime \prime \prime}(y) d y \\
& =\int_{\frac{\log \left(X / B_{d}(T)\right)-m}{s}}^{\infty}\left[\exp (s y+m)-\frac{X}{B_{d}(T)}\right] \ell_{k}(y) d y-\frac{\xi}{6} \int_{\frac{\log \left(X / B_{d}(T)\right)-m}{s}}^{\infty}\left[\exp (s y+m) \ell_{k}^{\prime \prime \prime}(y)\right] d y \\
& +\frac{\xi}{6} \int_{\frac{\log \left(X / B_{d}(T)\right)-m}{s}}^{\infty}\left[\frac{X}{B_{d}(T)} \ell_{k}^{\prime \prime \prime}(y)\right] d y
\end{aligned}
$$

We can simplify the equation step integration by parts progressively.

Let

$$
I=\int_{\frac{\log \left(X / B_{d}(T)\right)-m}{s}}^{\infty}\left[\exp (s y+m) \ell_{k}^{\prime \prime \prime}(y)\right] d y
$$

and $u(y)=e^{s y+m} \frac{d u}{d y}=s e^{s y+m} \quad d u=s e^{s y+m} d y$

$$
\begin{aligned}
& d v=\ell_{k}^{\prime \prime \prime}(y) d y \quad v=\ell_{k}^{\prime \prime}(y) \\
& \Rightarrow I=\ell_{k}^{\prime \prime}(y) e^{s y+m} \mid \begin{array}{l}
\infty \\
\frac{\log \left(X / B_{d}(T)\right)-m}{s}
\end{array} \\
& -\int_{\frac{\log \left(X / B_{d}(T)\right)-m}{s}}^{\infty} \ell_{k}^{\prime \prime}(y) s e^{s y+m} d y
\end{aligned}
$$




$$
\begin{aligned}
& =\ell_{k}^{\prime \prime}(y) e^{s y+m} \mid \frac{\infty}{\frac{\log \left(X / B_{d}(T)\right)-m}{s}} \\
& -s \int_{\frac{\log \left(X / B_{d}(T)\right)-m}{s}}^{\infty} \ell_{k}^{\prime \prime}(y) e^{s y+m} d y
\end{aligned}
$$

And so forth, we can obtain

$$
\begin{aligned}
& E\left[\max \left(Z_{f}(T, T)-\frac{X}{B_{d}(T)}\right)\right] \\
& =\int_{\frac{\log \left(X / B_{d}(T)\right)-m}{s}}^{\infty}\left[\exp (s y+m)-\frac{X}{B_{d}(T)}\right] \ell_{k}(y) d y \\
& -\frac{\xi}{6}\left\{\left[\ell_{k}^{\prime \prime}(y) e^{s y+m}\right]_{\frac{\log \left(X / B_{d}(T)\right)-m}{s}}^{\infty}-S\left[\left[\ell_{k}^{\prime}(y) e^{s y+m}\right]_{\frac{\log \left(X / B_{d}(T)\right)-m}{s}}^{\infty}-S\left[\left[\ell_{k}(y) e^{s y+m}\right]_{\frac{\log \left(X / B_{d}(T)\right)-m}{s}}^{\infty}\right.\right.\right. \\
& \left.\left.\left.-s \int_{\frac{\log \left(X / B_{d}(T)\right)-m}{s}}^{\infty} e^{s y+m} \ell_{k}(y) d y\right]\right]\right\}+\frac{\xi}{6}\left[\frac{X}{B_{d}(T)} \ell_{k}^{\prime \prime}(y)\right]_{\frac{\log \left(X / B_{d}(T)\right)-m}{s}}^{\infty} \\
& =\int_{\frac{\log \left(X / B_{d}(T)\right)-m}{s}}^{\infty}\left[\exp (s y+m)-\frac{X}{B_{d}(T)}\right] \ell_{k}(y) d y \\
& -\frac{\xi}{6}\left\{\left[\ell_{k}^{\prime \prime}(y) e^{s y+m}\right]_{\frac{\log \left(X / B_{d}(T)\right)-m}{s}}^{\infty}-s\left[\ell_{k}^{\prime}(y) e^{s y+m}\right]_{\frac{\log \left(X / B_{d}(T)\right)-m}{s}}^{\infty}+s^{2}\left[\ell_{k}(y) e^{s y+m}\right]_{\frac{\log \left(X / B_{d}(T)\right)-m}{s}}^{\infty}\right. \\
& \left.-s^{3} \int_{\frac{\log \left(X / B_{d}(T)\right)-m}{s}}^{\infty} e^{s y+m} \ell_{k}(y) d y\right\}+\frac{\xi}{6}\left[\frac{X}{B_{d}(T)} \ell_{k}^{\prime \prime}(y)\right]_{\frac{\log \left(X / B_{d}(T)\right)-m}{s}}^{\infty} \\
& E\left[\max \left(\mathrm{Z}_{f}(T, T)-\frac{X}{B_{d}(T)}\right)\right]=\frac{\mathrm{Z}_{f}(0, T)}{A+B}\left[\begin{array}{l}
p \int_{\frac{\log \left(X / B_{d}(T)\right)-m}{s}}^{\infty} \exp (s y) h_{0, \alpha}(y) d y \\
+(1-p) \int_{\frac{\log \left(X / B_{d}(T)\right)-m}{s}}^{\infty} \exp (s y) h_{0, \beta}(y) d y
\end{array}\right] \\
& -\frac{X}{B_{d}(T)}\left[p \int_{\frac{\log \left(X / B_{d}(T)\right)-m}{s}}^{\infty} h_{0, \alpha}(y) d y+(1-p) \int_{\frac{\log \left(X / B_{d}(T)\right)-m}{s}}^{\infty} h_{0, \beta}(y) d y\right] \\
& +\frac{\xi}{6} s \frac{X}{B_{d}(T)}\left[p h_{0, \alpha}^{\prime}\left(\frac{m-\log \left(X / B_{d}(T)\right)}{s}\right)+(1-p) h_{0, \beta}^{\prime}\left(\frac{m-\log \left(X / B_{d}(T)\right)}{s}\right)\right] \\
& +\frac{\xi}{6} s^{2} \frac{X}{B_{d}(T)}\left[p h_{0, \alpha}\left(\frac{m-\log \left(X / B_{d}(T)\right)}{s}\right)+(1-p) h_{0, \beta}\left(\frac{m-\log \left(X / B_{d}(T)\right)}{s}\right)\right]
\end{aligned}
$$

where

$$
A=p e^{\alpha^{2} s^{2} / 2} \quad B=(1-p) e^{\beta^{2} s^{2} / 2}
$$

Rearrange the above equation yields 


$$
\begin{gathered}
E\left[\max \left(\mathrm{Z}_{f}(T, T)-\frac{X}{B_{d}(T)}\right)\right] \\
=\frac{Z_{f}(0, T)}{A+B}\left[p \int_{\frac{\log \left(X / B_{d}(T)\right)-m}{s}}^{\infty} \exp (s y)\left(\frac{1}{\sqrt{2 \pi \alpha^{2}}} e^{\frac{-y^{2}}{2 \alpha^{2}}}\right) d y+(1-p) \int_{\frac{\log \left(X / B_{d}(T)\right)-m}{s}}^{\infty} \exp (s y)\left(\frac{1}{\sqrt{2 \pi \beta^{2}}} e^{\frac{-y^{2}}{2 \beta^{2}}}\right) d y\right] \\
+\frac{X}{6} S \frac{X}{B_{d}(T)}\left[p \frac{1}{\sqrt{2 \pi \alpha^{2}}} e^{\frac{-\left(\frac{m-\log \left(X / B_{d}(T)\right.}{s}\right)^{2}}{2 \alpha^{2}} \cdot \frac{-\left(\frac{m-\log \left(X / B_{d}(T)\right.}{s}\right)}{\alpha^{2}}}+(1-p) \frac{1}{\sqrt{2 \pi \beta^{2}}} e^{\left.\frac{-\left(\frac{m-\log \left(X / B_{d}(T)\right.}{s}\right)^{2}}{2 \beta^{2}} \cdot \frac{-\left(\frac{m-\log \left(X / B_{d}(T)\right.}{s}\right)}{\beta^{2}}\right]}\right] \\
+\frac{\xi}{6} s^{2} \frac{X}{B_{d}(T)}\left[p \frac{1}{\sqrt{2 \pi \alpha^{2}}} e^{\frac{-\left(\frac{m-\log \left(X / B_{d}(T)\right)}{s}\right)^{2}}{2 \alpha^{2}}}+(1-p) \frac{1}{\sqrt{2 \pi \beta^{2}}} e^{\left.\frac{-\left(\frac{m-\log \left(X / B_{d}(T)\right)}{s}\right)^{2}}{2 \beta^{2}}\right]}\right]
\end{gathered}
$$

Transforming $h_{\alpha^{2} s, \alpha}, h_{\beta^{2} s, \beta}, h_{0, \alpha}, h_{0, \beta}$ into $h_{0,1}$ by normalizing gives

$$
\begin{gathered}
E\left[\max \left(\mathrm{Z}_{f}(T, T)-\frac{X}{B_{d}(T)}\right)\right] \\
=Z_{f}(0, T)\left\{\frac{A}{A+B} \int_{\frac{\log \left(X / B_{d}(T)\right)-\alpha^{2} s^{2}-m}{\alpha s}}^{\infty} h_{0,1}(y) d y+\frac{B}{A+B} \int_{\frac{\log \left(X / B_{d}(T)\right)-\beta^{2} s^{2}-m}{\beta s}}^{\infty} h_{0,1}(y) d y\right\} \\
-\frac{X}{B_{d}(T)}\left\{p \int_{\frac{\left(\log \left(X / B_{d}(T)-m\right)\right.}{(\alpha s)}}^{\infty} h_{0,1}(y) d y+(1-p) \int_{\frac{\left(\log \left(X / B_{d}(T)-\mathrm{m}\right)\right.}{(\beta s)}}^{\infty} h_{0,1}(y) d y\right\} \\
+\frac{\xi s}{6} \frac{X}{B_{d}(T)}\left\{\frac{p}{\alpha}\left[s-\frac{m-\log \left(X / B_{d}(T)\right)}{\alpha^{2} s}\right] h_{0,1}\left(\frac{m-\log \left(X / B_{d}(T)\right)}{\alpha s}\right)\right. \\
\left.+\frac{1-p}{\beta}\left[s-\frac{m-\log \left(X / B_{d}(T)\right)}{\beta^{2} s}\right] h_{0,1}\left(\frac{m-\log \left(X / B_{d}(T)\right)}{\beta s}\right)\right\}
\end{gathered}
$$

It follows by the cumulative normal distribution function, $N(x)=\int_{-\infty}^{x} h_{0,1}(y) d y$, that

Finally, we can write a currency call option as

$$
\begin{gathered}
E\left[\max \left(Z_{f}(T, T)-\frac{X}{B_{d}(T)}, 0\right)\right] \\
=Z_{f}(0, T)\left[\frac{A}{A+B} N\left(d_{1}\right)+\frac{B}{A+B} N\left(d_{2}\right)\right]-\frac{X}{B_{d}(T)}\left[p N\left(d_{3}\right)+(1-p) N\left(d_{4}\right)\right] \\
+\frac{\xi s}{6} \frac{X}{B_{d}(T)}\left[\frac{p}{\alpha}\left(s-\frac{d_{3}}{\alpha}\right) n\left(d_{3}\right)+\frac{1-p}{\beta}\left(s-\frac{d_{4}}{\beta}\right) n\left(d_{4}\right)\right] \quad \because Z_{f}(0, T)=P_{f}(0, T) S_{d}(0)
\end{gathered}
$$




$$
\begin{gathered}
=P_{f}(0, T) S_{d}(0)\left[\frac{A}{A+B} N\left(d_{1}\right)+\frac{B}{A+B} N\left(d_{2}\right)\right]-\frac{X}{B_{d}(T)}\left[p N\left(d_{3}\right)+(1-p) N\left(d_{4}\right)\right] \\
+\frac{\xi s}{6} \frac{X}{B_{d}(T)}\left[\frac{p}{\alpha}\left(s-\frac{d_{3}}{\alpha}\right) n\left(d_{3}\right)+\frac{1-p}{\beta}\left(s-\frac{d_{4}}{\beta}\right) n\left(d_{4}\right)\right]
\end{gathered}
$$

\section{Appendix B}

Under the new measure $Q$, we can write

$$
\frac{d Z_{f}(t, T)}{Z_{f}(t, T)}=\sum_{i=1}^{4}\left[a_{f i}(t, T)+\delta_{d i}(t)\right] d \widetilde{W}_{i}(t)
$$

according to Itô Lemma :

$$
d \log Z_{f}(t, T)=-\frac{1}{2} \sum_{i=1}^{4}\left[a_{f i}(v, T)+\delta_{d i}(v)\right]^{2} d v+\sum_{i=1}^{4}\left[a_{f i}(t, T)+\delta_{d i}(t)\right] d \widetilde{W}_{i}(t)
$$

The expected value under risk-neutral measure of $Z_{f}(T, T)$ is

$\widetilde{E}\left[Z_{f}(T, T)\right]$

$$
=\widetilde{E}\left\{Z_{f}(0, T) \exp \left(\left[\sum_{i=1}^{4} \int_{0}^{T}\left[a_{f i}(t, T)+\delta_{d i}(t)\right] d \widetilde{W}_{i}(t)\right]-\frac{1}{2} \sum_{i=1}^{4} \int_{0}^{T}\left[a_{f i}(v, T)+\delta_{d i}(v)\right]^{2} d v\right)\right.
$$

The instantaneous standard deviation of $Z_{f}(T, T)$ is $\left[a_{f i}(t, T)+\delta_{d i}(t)\right]$.

$$
\left[a_{f i}(t, T)+\delta_{d i}(t)\right]=\sigma_{Z_{f i}}(t, T) \quad i=1,2,3,4
$$

We know that $a_{d i}(t, T)=-\int_{t}^{T} \sigma_{d i}\left(t, u, f_{d}(t, u)\right) d u \quad i=1,2$

And for simplicity, the instantaneous variance is

$$
\left[a_{f i}(t, T)+\delta_{d i}(t)\right]^{2}=\sigma_{z_{f i}}^{2}(t, T)
$$

Under risk-neutral measure:

$$
\begin{gathered}
\widetilde{E}\left[Z_{f}(T, T)\right]=\widetilde{E}\left[Z_{f}(0, T) \exp \left(\left[\sum_{i=1}^{4} \int_{0}^{T} \sigma_{\square_{f i}}(v, T) d \widetilde{W}_{i}(v)\right]-\frac{1}{2} \sum_{i=1}^{4} \int_{0}^{T} \sigma_{Z_{f i}}^{2}(v, T) d v\right)\right] \\
=Z_{f}(0, T) \exp \left(-\frac{1}{2} \sum_{i=1}^{4} \int_{0}^{T} \sigma_{Z_{f i}}^{2}(v, T) d v\right) * \widetilde{E}\left[\exp \left(\sum_{i=1}^{4} \int_{0}^{T} \sigma_{\square_{f i}}(v, T) d \widetilde{W}_{i}(v)\right)\right] \\
\because \sigma_{\square_{f i}} d \widetilde{W}_{i} \sim N\left(0, \sigma_{Z_{f i}}^{2} d t\right) i=1,2,3,4
\end{gathered}
$$

The moment generating function of a random variable $X$ is the function

$$
M(t)=\left(e^{t x}\right)=\exp \left(\mu t+\frac{\sigma^{2} t^{2}}{2}\right)
$$

when $t=1$ 


$$
\begin{aligned}
\widetilde{E}\left[\exp \left(\sum_{i=1}^{4} \int_{0}^{T} \sigma_{\square_{f i}}(v, T) d \widetilde{W}_{i}(v)\right)\right]=\exp \left(\frac{1}{2} \sum_{i=1}^{4} \int_{0}^{T} \sigma_{Z_{f i}}^{2}(v, T) d v\right) \\
\widetilde{E}\left[Z_{f}(T, T)\right]=Z_{f}(0, T) \exp \left(-\frac{1}{2} \sum_{i=1}^{4} \int_{0}^{T} \sigma_{Z_{f i}}^{2}(v, T) d v\right) * \exp \left(\frac{1}{2} \sum_{i=1}^{4} \int_{0}^{T} \sigma_{Z_{f i}}^{2}(v, T) d v\right) \\
=Z_{f}(0, T)
\end{aligned}
$$

From above equation, it shows the expected value of $Z_{f}(T, T)$ is the same as the initial value of $Z_{f}(T, T)$. The mean of underlying asset $Z_{f}(T, T)$ under the risk-neutral measure is

$$
\begin{gathered}
m=\log \left(Z_{f}(0, T)\right)-\log \left\{\left(1+\frac{\xi s^{3}}{6}\right)\left[p e^{\alpha^{2} s^{2} / 2}+(1-p) e^{\beta^{2} s^{2} / 2}\right]\right\} \\
=\log \left(Z_{f}(0, T)\right)-\log (A+B)-\log \left(1+\frac{\xi s^{3}}{6}\right) \\
A=p e^{\alpha^{2} s^{2} / 2} \quad B=(1-p) e^{\beta^{2} s^{2} / 2}
\end{gathered}
$$

\section{REFERENCES}

[1] Aggarwal, R., 1990, "Distribution of Spot and Forward Exchange Rates: Empirical Evidence and Investor Valuation of Skewness and Kurtosis." Decision Sciences 21, 588-595.

[2] Amin, K. I. and R.A. Jarrow, 1991, "Pricing Foreign Currency Options under Stochastic Interest Rates." Journal of International Money and Finance 10, 310-319.

[3] Bakshi, G., C. Cao and Z. Chen, 1997, "Empirical Performance of Alternative Option Pricing Models." The Journal of Finance 52, 2003-2049.

[4] Bates, D. S., 1996, "Jumps and Stochastic Volatility: Exchange Rate Processes Implicit in Deutsche Mark Options." The Review of Financial Studies 9, 69-107.

[5] Biger, N. and J. Hull, 1983, "The Valuation of Currency Options.” Financial Management 12, 24-28.

[6] Black, F. and M. Scholes, 1973, "The Pricing of Options and Corporate Liabilities." Journal of Political Economy 81, 637-659.

[7] Campa, J. M., P. K. Chang and R. L. Reider, 1998, "Implied Exchange Rate Distributions: Evidence from OTC Option Markets." Journal of International Money and Finance 17, 117-160.

[8] Chesney, M. and L. Scott, 1989, "Pricing European Currency Options: A Comparison of the Modified Blacke-Scholes Model and a Random Variance Model." Journal of Financial and Quantitative Analysis 24, 267-284.

[9] Choi, S. and M. D. Marcozzi, 2003, "The Valuation of Foreign Currency Options under Stochastic Interest Rates." Computers \& Mathematics with Applications 46, 741-748.

[10] Corrado, C. J. and T. Su, 1996, "Skewness and Kurtosis in S\&P 500 Index Returns Implied by Option Prices." Journal

of Financial Research 19, 175-192.

[11] Cox, J. C., E. Ingersoll and S.A. Ross, 1985, "A Theory of the Term Structure of Interest Rates.” Econometrica 53, 385-407.

[12] Dong, M. Y., M. T. Yu, C.C. Chang and S.L. Chung, 2002, "Pricing Currency Options under CIR Interest Rate Process and Stochastic Volatility." Journal of Management 19, 707-735.

[13] Dupire, B., 1994, "Pricing with a Smile." RISK, 18-20.

[14] Ahn, D. H. and B. Gao, 2003, "Locally Complete Markets, Exchange Rates and Currency Options." Review of Derivatives Research 6, 5-26.

[15] Grabbe, J. O., 1983, "The Pricing of Call and Put Option on Foreign Exchange." Journal of International Money and Finance 2, 239-253.

[16] Gaman, M. B. and S.W. Kohlhagen, 1983, "Foreign Currency Option Values." Journal of International Money and Finance 2, 231-237.

[17] Heath, D., R. Jarrow and A. Morton, 1992, "Bond Pricing and the Term Structure of Interest Rates: A New Methodology for Contingent Claims Valuation.” Econometrica 60, 77-105.

[18] Heston, S. L., 1993, “A Closed-Form Solution for Options with Stochastic Volatility with Applications to Bond and Currency Options." The Review of Financial Studies 6, 327-343.

[19] Hilliard, J. E., J. Madura and A. L. Tucker, 1991, “Currency Option Pricing with Stochastic Domestic and Foreign Interest Rates." Journal of Financial and Quantitative Analysis 26, 139-151.

[20] Jarrow, R. and A. Rudd, 1982, “Approximate Option Valuation for Arbitrary Stochastic Processes." Journal of Financial Economics 10, 347-369.

[21] Ki, H., B. Choi, K. H. Chang and M. Lee, 2005, "Option Pricing under Extended Normal Distribution." Journal of Futures Markets 25, 845-871. 
[22] Kou, S. G., 2002, "A Jump- Diffusion Model for Option Pricing.” Management Science 48, 1086-1101.

[23] Lewis, A. L., 2001, "A Simple Option Formula for General Jump-Diffusion and Other Exponential Levy Processes." Envision Financial Systems and OptionzCity.net.

[24] Malz, A. M., 1996 "Using Option Prices to Estimate Realignment Probabilities in the European Monetary System: the Case of Sterling-mark." Journal of International Money and Finance 15, 717-748.
[25] Scott, L. O., 1997, "Pricing Stock Option in a Jump Diffusion Model with Stochastic Volatility and Interest Rates: Applications of Fourier Inversion Methods." Mathmetical Finance 7, 413-424.

[26] Sherrick, B. J., P. Garcia and V. Tirupattur, 1996, "Recovering probabilistic information from option markets: tests of distributional assumptions." Journal of Futures Markets 16, 545-560.

[27] Vasicek, O., 1976, "An Equilibrium Characterization of the Term Structure.” Journal of Financial Economics 5, 177-188. 